\title{
Human Computer Interaction \& Health Activism
}

$\begin{array}{ll}\begin{array}{l}\text { Reem Talhouk } \\ \text { Kellie Morrissey }\end{array} & \begin{array}{l}\text { Emma Simpson } \\ \text { Lydia Emma Michie }\end{array} \\ \begin{array}{l}\text { Open Lab, Newcastle University } \\ \text { Open Lab, Newcastle University } \\ \text { R.R.Talhouk2@ncl.ac.uk } \\ \text { Kellie.Morrissey@ncl.ac.uk }\end{array} & \begin{array}{l}\text { Newcastle upon Tyne, UK } \\ \text { emma.simpson@ncl.ac.uk }\end{array} \\ \text { L.E.Michie2@ncl.ac.uk } \\ \text { Sarah Fox } & \text { Madeline Balaam } \\ \text { University of Washington } & \text { Media Technology and Interaction } \\ \text { Seattle, United States } & \text { Design, KTH Royal Institute of } \\ \text { sefox@uw.edu } & \text { Technology } \\ \text { Nadia Pantidi } & \text { Stockholm, Sweden } \\ \text { University College Cork } & \text { balaam@kth.se } \\ \text { Cork, Ireland } & \\ \text { konstantia.pantidi@ucc.ie } & \end{array}$

Permission to make digital or hard copies of part or all of this work for personal or classroom use is granted without fee provided that copies are not made or distributed for profit or commercial advantage and that copies bear this notice and the full citation on the first page. Copyrights for third-party components of this work must be honored. For all other uses, contact the Owner/Author.

CHI'18 Extended Abstracts, April 21-26, 2018, Montréal, QC, Canada (C) 2018 Copyright is held by the owner/author(s).

https://doi.org/10.1145/3170427.3185369

\begin{abstract}
In both developing and developed countries, policies implemented by governments are affecting the health of already marginalized communities. Within the $\mathrm{HCI}$ community there are examples of implicit and explicit forms of health activism as well as sub-communities adopting an activist approach to address issues of social justice that ultimately influence the social determinants of health. This SIG aims to bring together these groups of $\mathrm{HCI}$ scholars to outline an agenda for health activism and research-identifying and highlighting characteristics of this burgeoning domain.
\end{abstract}

\section{Author Keywords}

Health; Activism; Policy; Health Activism

\section{ACM Classification Keywords}

H.5.m. Information interfaces and presentation

\section{Introduction}

Health policies and reforms have recently been subject to much debate [3]. Socio-economic, cultural and environmental conditions determine the health of populations (see figure 1, top) and are, in turn, strongly influenced by the political and economic milieu [9]. The interplay between these conditions and their effect on health has been further engrained in the Sustainable Development Goals (SDG). The process of 


\section{Examples of social determinants of health include (World Health Organization):}

1. Income and social status

2. Education

3. Physical environment (e.g. safe water)

4. Social support networks

5. Access to health services

\section{Examples of the interplay between the Health SDG and other SDGs (World Health Organization):}

Quality Education (SDG4): Supporting high quality education for all to improve health and health equity

Reduced inequalities (SDG10): Ensuring equitable access to health services

\section{Sustainable cities and} communities (SDG11): Fostering healthier cities

Figure 1: How health is determined by wider socio-political and economic factors achieving Good Health and Wellbeing (SDG3) is strongly influenced by factors embedded within other areas the SDGs address (figure 1). Such models highlight how policies implemented in health and nonhealth related areas impact health and the social determinants of health, respectively.

We are currently witnessing how the political climate is furthering the marginalization of vulnerable communities. In the U.S., the Trump administration's elimination funding for reproductive and women's health is expected to have a lasting impact on the further marginalization of women within the healthcare system [14]. In the case of U.K., Brexit is predicted to negatively impact healthcare financing and contribute to the loss of qualified immigrant staff [13], highlighting how political debates around the economy and national identity can permanently effect the daily lives of healthcare workers and patients.

In developing countries, academics have highlighted that the marginalization of vulnerable communities (e.g. refugees) is further exacerbated in contexts rife with discord, corruption and political instability due to lack of clarity regarding health accountability [4]. Even in non-conflict settings, responsibility regarding response to health crises are questioned, with, for example, the World Health Organization facing criticism regarding its slow response to the Ebola outbreak in West Africa [6]. Additionally, tokenistic health policies that disregard root socio-cultural causes result in the further marginalization of vulnerable communities. For example, in India, phone manufacturers are mandated by the government to install panic buttons in phones that would put women in contact with emergency services as a means to counteract sexual harassment and violence against women. However, women interviewed identified that this would not be effective if the emergency taskforce (e.g. police) remain underresourced [7]. While the policy intends to help mitigate violence, it fails to address the root cause through public health awareness campaigns on gender equality and sexual rights and the integration of such notions into school curriculums, for example.

\section{HCI \& Health Activism}

Forms of health activism, implicit and explicit, are found within $\mathrm{HCI}$ research as part of attempts to address some of the social inequalities of health. Somewhat implicit examples of health activism have, for example, come in the form of studies in which researchers support the design and development of mobile apps to be used by citizens, and, in turn, to inform public health policy makers and practitioners [10]. Taking up a more explicitly activist stance, Parker et al [9] discuss how technologies can address social inequalities-as a medium through which power relations can be disrupted and social change may be pursued. Mosaic, a system designed and deployed by Parker et al [9], provided a platform to facilitate health activism through the sharing of ideas and experiences of healthy eating on a budget in low-income

communities. In another example of health activism, Talhouk et al examined technology not only as a means of improving access to healthcare services to refugees, but also as a means to increase the agency of refugees through increasing their control over their interactions with healthcare providers [11]. More recent work around abortion rights advocacy in Ireland highlights the role of $\mathrm{HCI}$ in raising awareness, encouraging dialogue and mobilizing communities to take action [8]. 


\section{Academic Activists}

Academics in the U.S. attended the Women's Marches, protests against decisions made by the Trump administration, and also contributed to estimating the number of people that attended the protests as a measure of the success of the movement [12].

A professor in the United Kingdom are challenging the increasing costs of higher education[1].

Public Health academics in Lebanon have set up the knowledge to Policy Center that advocates for policy reform in a number of areas including healthcare provision [2].

A professor in India attempted to protect students during their protest against sexual harassment at their university [5].

Figure 2 Examples of activism enacted by academics
In parallel, we have witnessed increasing research tackling social and health inequalities with an activist approach within the HCI community (figure 3 ). Such events indicate a movement within the community towards formally coming together to address issues of health justice. However, events still seem to be dispersed across several sub-communities within HCI. Given the current controversial nature of health policies and health inequalities being propagated across the political landscape, this dispersed activity within HCI to address health justice, and the difficulties in being academic health activists, we propose this SIG as a space to bring together $\mathrm{HCI}$ researchers to discuss and identify the roles $\mathrm{HCI}$ and $\mathrm{HCI}$ researchers are taking on within health activism.

\section{HCI \& Health Activism SIG}

This SIG aims to engage with the HCI community to (1) identify current research that implicitly and explicitly engage in health activism, (2) highlight characteristics of health activism in $\mathrm{HCI}$ and health activists in the $\mathrm{HCI}$ community, as well as (3) emphasize how forms of activism in non-health related $\mathrm{HCI}$ fields can address the social determinants of health.

We aim bring together $\mathrm{HCI}$ researchers interested in health, social justice, civic empowerment, activism and advocacy to discuss the ways in which $\mathrm{HCI}$ research is currently addressing social inequalities in health and how it is implicitly and/or explicitly engaging with the politics of health. We will target audiences of events and workshops, previously mentioned, that have had an activist HCI approach. Additionally, twitter and other social media forums will be utilized before and during the conference to inform attendees of the SIG and to highlight how current research being presented at
CHI2018 is relevant to health activism. CHI2018 attendees will be encouraged to contribute to the discussion beforehand through an online forum that will be created as part of the SIG's website.

SIG attendees will be encouraged to discuss their work in conjunction with other attendees to identify ways in which health activism is implicitly and explicitly enacted within $\mathrm{HCI}$ research. Discussions will be further

facilitated through encouraging attendees to consider:

1) The role of HCI data (e.g. citizen-generated data) in health activism?

2) The current role of $\mathrm{HCI}$ in activism (what health justice issues are being addressed by $\mathrm{HCI}$ researchers)?

3) How HCI studies and technological designs can play an implicit and/or explicit role in health activism?

4) How do HCI researchers perceive themselves as health activists?

5) How can HCI support health activism?

Based on the discussions, SIG attendees will identify what the characteristics of HCI health activists and their work might be. Characteristics will be prioritized in a manner that would allow for a short self-assessment questionnaire (a series of three to four questions) to be collectively designed that assesses whether researchers and their work can be characterized as HCI health activism. The activity will aid in the creation of a workable definition of health activism and academic health activists within HCI. The questions will be disseminated through social media at CHI2018 as a means of surfacing the implicit ways in which health activism is already being enacted within the $\mathrm{HCI}$ 


\section{Academic Activist \\ Events in HCI}

\section{HCIxDementia Workshop:}

Focused on the political

dimensions of medicalized

designs

\section{Hacking Women's Health}

Hackathon that addressed

issues of taboo, prejudice and power through women

centered design

\section{Exploring Social Justice,}

\section{Design and HCI: Workshop}

exploring interaction design and technology through the lens of social justice

\section{HCI, Politics and the City}

HCI workshop that aimed to

formulate concrete strategies for bottom-up activism

Digital Civics: SIG on how technologies can reconfigure relationships between citizens, communities and the state

Figure 3 Events at HCI conferences with an activist approach community and to raise awareness regarding the need for health activism within the current political climate. The discussions and outputs of the SIG will inform future workshops around $\mathrm{HCI}$ and health activism.

\section{Acknowledgements}

This work is funded by EPSRC EP/L016L76/1, VR 201705133 and NSF 1523579, 1423074

\section{References}

1. Academic activist hits out at higher education policies | Education | The Guardian. Retrieved January 13, 2018 from

https://www.theguardian.com/education/2011/dec/05/ simon-szreter-attacks-government-policies

2. Lincoln C. Chen, Tim G. Evans, and Richard A. Cash. 1999. Health as a Global Public Good. Retrieved January 13, 2018 from http://s1.downloadmienphi.net/file/downloadfile6/151/ 1384343.pdf \#page $=322$

3. Julie Hirschfeld Davis. 2017. Trump Signs Law Taking Aim at Planned Parenthood Funding - The New York Times. Retrieved January 10, 2018 from

https://www.nytimes.com/2017/04/13/us/politics/plan ned-parenthood-trump.htm

4. Abbas El-Zein, Jocelyn DeJong, Philippe Fargues, Nisreen Salti, Adam Hanieh, and Helen Lackner. 2016. Who's been left behind? Why sustainable development goals fail the Arab world. The Lancet 388, 10040: 207210. http://doi.org/http://doi.org/10.1016/S01406736(15)01312-4

5. Mark Exworthy. 2017. The NHS and Brexit. Retreived January 15, 2018 from

https://www.birmingham.ac.uk/research/perspective/n hs-and-brexit.aspx

6. Adam Kamradt-Scott. 2016. WHO's to blame? The World Health Organization and the 2014 Ebola outbreak in West Africa. Third World QuarTerly 37, 3: 401-418. http://doi.org/10.1080/01436597.2015.1112232

7. Naveena Karusala and Neha Kumar. 2017. Women's
Safety in Public Spaces: Examining the Efficacy of Panic Buttons in New Delhi. In Proceedings of the CHI Conference on Human Computer Interaction (CHI'17), 3340-3351. http://doi.org/10.1145/3025453.3025532

8. Lydia Michie, Madeline Balaam, John McCarthy, Timur Osadchiy, and Kellie Morrissey. 2018. From Her Story, to Our Story: Digital Storytelling as Public Engagement around Abortion Rifghts Advocacy in Ireland. Proceedings of the CHI Conference on Human Computer Interaction (CHI'18), In Press.

9. Andrea Grimes Parker. 2013. Designing for health activism. Interactions 20, 22. http://doi.org/10.1145/2427076.2427082

10. Emma Simpson, Rob Comber, Andrew Garbett, Ed Ian Jenkins, and Madeline Balaam. 2017. Experiences of Delivering a Public Health Data Service. In Proceedings of the CHI Conference on Human Factors in Computing Systems (CHI'17), 6171-6183. http://doi.org/http://doi.org/10.1145/3025453.3025881

11. Reem Talhouk, Tom Bartindale, Kyle Montague, et al. 2017. Implications of Synchronous IVR Radio on Syrian Refugee Health and Community Dynamics. In Proceedings of the 8th International Conference on Communities and Technologies (C\&T'17), 10 pages. http://doi.org/10.1145/3083671.3083690

12. The Exhausting Work of Tallying the Women's March America's Largest Protest - The Atlantic. Retrieved January 13, 2018 from

https://www.theatlantic.com/technology/archive/2017/ 01/womens-march-protest-count/514166/

13. American University of Beirut - Knowledge to Policy (K2P) Center - Kowledge to Policy (K2P) Centre for Health. Retrieved January 13, 2018 from https://website.aub.edu.lb/k2p/Pages/index.aspx

14. "I kept saying I was a teacher, but police never listened and continued to beat me", BHU professor recounts ordeal | The Indian Express. Retrieved January 13, 2018 from http://indianexpress.com/article/india/bhuviolence-women-professor-attacked-police-lathichargeyogi-adityanath-sexual-harassment-protests-4863821/ 